\title{
PROFESSOR Dr. Dr. h.c. HEINZ BETHGE
}

\section{IN HONOUR OF HIS 60th BIRTHDAY}

On the 15th of November Professor Heinz Bethge celebrates his 60th birthday. He is Director of the Institute of Solid State Physics and Electron Microscopy of the Academy of Sciences of the GDR. Professor Bethge is a member of several Academies of Sciences, and since 1974 he has been President of the Deutsche Akademie der Naturforscher Leopoldina. He acts in various international committees and scientific societies and is member of the Board of Editors of several scientific journals, among others of physica status solidi (a).

Professor Bethge, born in Magdeburg, commenced his studies at the Technische Hochschule Berlin-Charlottenburg. After an interruption during the war he continued his studies at the University of Halle where he took his degree of a Dr. rer. nat. at the Institute of Physics. He belonged to the staff of this institute, until in 1960 he was appointed full Professor of Physics at the University of Halle and changed over to the Academy of Sciences of the GDR to lay the basis for the later Institute of Solid State Physics and Electron Microscopy.

Professor Bethge's research work in the field of solid state physics and electron microscopy published in a great number of papers and well-known to the scientists in this field, is especially related to the detection of molecular processes on crystal surfaces on the one hand, and to the development of special electron microscopical methods on the other hand. Professor Bethge's experimental detection of critical quantities in surface physics, like diffusion lengths, were valuable contributions which were also important for the theory of crystal growth. Furthermore, his basic research work in the field of interfaces and thin layer (misfit, adsorption, epitaxy) has to be mentioned; it gave important impulses also for the applied research, e.g. influencing the field of solid state electronics. Professor Bethge's leading work in the field of the dependence of mechanical properties on the real structure of crystalline solids (strength, plasticity, fracture behaviour) from the beginning of the sixties is now continued by his co-workers under his guidance. Always seeing the unity between research problem and research method, Professor Bethge developed or improved electron microscopical methods, especially in the field of the non-conventional electron microscopy (surface electron microscopy, surface decoration). The electron microscopical methods nowadays applied in his institute also include the modern highvoltage electron microscopy, which - using $1000 \mathrm{keV}$ electrons - is able to transmit specimens with thicknesses up to some microns.

By his inventiveness, his far-sightedness in science and his creative activity, Professor Bethge is highly esteemed by his colleagues, his co-workers and in national and international bodies. Especially appreciated by all of them is his unconventional way of giving advice and helping, not only in solving scientific problems, but also in personal matters. Acknowledging with gratitude the many years of fruitful common work, his friends, his colleagues and the co-workers of his institute wish him many years of creativeness and good health. The editors of physica status solidi fall in with these wishes and add their gratefulness for his constant engagement as a member of the Editorial Board. 
